\title{
Enfisema orbitário compressivo após asseio nasal: relato de caso
}

\section{Sight-threatening orbital emphysema after nose blowing: case report}

\author{
Brunode Albuquerque Furlani ${ }^{1}$ \\ Bruno Diniz $^{2}$ \\ Luis Gustavo Bitelli ${ }^{3}$ \\ Elisabeth Nogueira Martins ${ }^{4}$
}

\section{RESUMO}

O enfisema orbitário é caracterizado pela presença anormal de ar na órbita. Sua ocorrência espontânea não é frequente e a maioria dos casos está associada à fratura de órbita. Relatamos o caso de uma paciente do sexo feminino de 40 anos com quadro de enfisema orbitário unilateral, secundário a asseio vigoroso do nariz. A paciente evoluiu com redução aguda da acuidade visual em decorrência de elevação da pressão intraocular, sendo indicado tratamento de urgência. Foi realizada punção orbitária com agulha 24-gauge próximo à região da incisura supraorbital, com melhora imediata do quadro clínico e recuperação da acuidade visual.

Descritores: Enfisema/etiologia; Doenças orbitárias; Pressão/efeitos adversos; Acuidade visual; Hipertensão ocular; Relatos de casos [Tipo de publicação]

\section{INTRODUÇÃO}

O enfisema orbitário é uma condição incomum caracterizada pela presença anormal de ar na órbita ${ }^{(1)}$. Na maior parte dos casos está associado a um traumatismo contuso orbitário, com fratura da parede óssea medial ${ }^{(2)}$. Pode também ser de aparecimento espontâneo ou relacionado ao ato de espirrar e assoar o nariz. É normalmente uma condição benigna, não relacionada à perda visual, sendo, na maioria das vezes, o paciente apenas observado até a resolução do problema, sem necessidade de intervenção.

Relatamos o caso de uma paciente que apresentou enfisema orbitário com quadro de redução de acuidade visual aguda, no qual houve necessidade de tratamento de urgência.

\section{RELATO DO CASO}

Paciente de 40 anos, sexo feminino, procurou Pronto Socorro de Oftalmologia do Hospital São Paulo - UNIFESP, referindo inchaço da região orbitária à esquerda há oito horas, acompanhada de dor de leve intensidade na mesma região e resfriado há alguns dias. A paciente negava alteração na acuidade visual ou febre. Relatava leve trauma na região parietal, sem acometimento da face, três dias antes, sem ter procurado auxílio médico no dia, e sem repercussões clínicas após o mesmo. Negava qualquer antecedente oftalmológico e referia história de etilismo.

Ao exame oftalmológico apresentava limitação discreta da abertura palpebral esquerda. Nas versões, notou-se leve limitação na elevação do olho esquerdo, assim como discreta distopia inferior deste olho, sugerindo efeito de massa com origem na parte superior da órbita, edema moderado das pálpebras superior e inferior à esquerda (Figura 1A), sem escoriações ou equimoses, com 


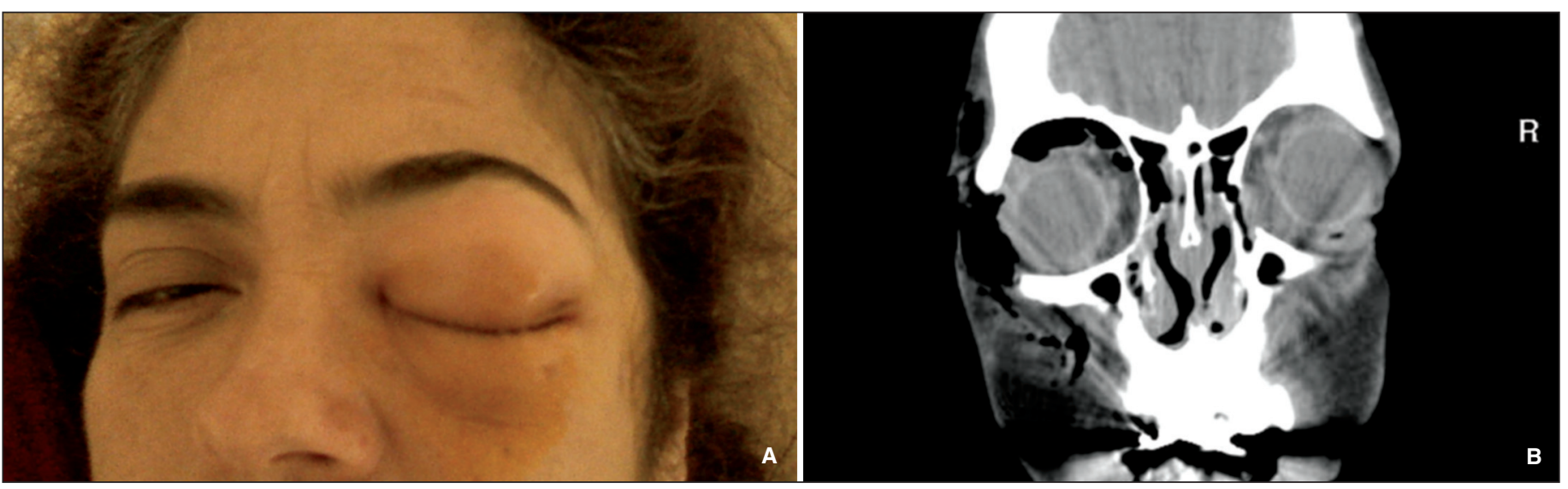

Figura 1 - A) Edema bipalpebral sem sinais inflamatórios à esquerda; B) Plano frontal de TC de crânio, mostrando ar em região extraconal superior e subcutânea temporal à esquerda

crepitação. A acuidade visual (com correção) era de 1,0 em ambos os olhos, os reflexos pupilares direto e consensual eram normais e a biomicroscopia mostrava apenas hiperemia conjuntival leve ao redor da córnea de aspecto congestivo no olho esquerdo. A pressão intraocular era $12 \mathrm{mmHg}$ no olho direito e $23 \mathrm{mmHg}$ no olho esquerdo. Não foram observadas alterações à fundoscopia em ambos os olhos.

Após realização de tomografia computadorizada de órbitas, observou-se enfisema orbitário à esquerda, possivelmente secundário ao asseio vigoroso do nariz. $\mathrm{O}$ exame mostrava presença significativa de ar na região superolateral da órbita esquerda (Figura 1B), não foi possível identificar a possível descontinuidade da lâmina papirácea neste lado.

A conduta inicial incluiu antibioticoterapia profilática (cefalexina $1 \mathrm{~g} / \mathrm{dia}$ ) oral e anti-histamínico (loratadina $10 \mathrm{mg} / \mathrm{dia}$ ) para reduzir a secreção nasal. A paciente foi orientada a não assoar o nariz, manter repouso e retornar no dia seguinte para reavaliação.

Algumas horas após o atendimento inicial a paciente apresentou piora do edema e da dor, após ter espirrado várias vezes. Foi, então, reavaliada e, neste momento, foi constatado edema importante das pálpebras esquerdas, impossibilitando a abertura espontânea do olho esquerdo. A acuidade visual segundo a tabela de Snellen, medida com dificuldade, era de 0,6. Não foi realizada avaliação dos reflexos, já que a paciente ainda apresentava midríase medicamentosa. A pressão intraocular à avaliação bidigital estava significantemente aumentada. No exame de fundo de olho era possível observar pulsação arterial na região do disco óptico.

Devido à hipótese diagnóstica de enfisema orbitário com sinais de compressão do nervo óptico e risco de comprometimento visual permanente, foi realizada uma punção orbital com agulha fina, após consentimento da paciente. A punção foi realizada sob anestesia local e condições assépticas, introduzindo-se uma agulha 24 gauge (KDL, São Paulo), montada em uma seringa de $10 \mathrm{ml}$ sem êmbolo e com solução salina em seu interior, foi inserida na região superomedial orbitária, próximo à incisura supraorbital paralela ao teto, em manobra simi- lar à anestesia peribulbar (Figura 2). A região da punção foi direcionada pela tomografia computadorizada, que revelou maior quantidade de ar na região extraconal superior. Com a punção, houve erupção de bolhas para dentro da seringa, evidenciando o sucesso do procedimento, inclusive com redução imediata do volume das pálpebras. No dia seguinte, a paciente apresentava melhora significativa do edema palpebral, motilidade ocular preservada, acuidade visual de 1,0, pressão intraocular de $13 \mathrm{mmHg}$ e biomicroscopia anterior e fundoscopia dentro da normalidade. Nenhuma intervenção adicional foi necessária.

A paciente foi acompanhada por três meses e não apresentou novo episódio.

\section{COMENTÁRIOS}

No enfisema orbitário relacionado ao trauma, a lâmina papirácea, que compõe a parede medial, é o local onde mais se encontra o defeito ósseo, mas a parede inferior também é sítio comum, principalmente nas fraturas em blowout ${ }^{(1)}$. Sua ocorrência na ausência de fratura é rara.

O enfisema é resultado de uma comunicação de seio da face com a órbita, produzida por fratura óssea e descontinuidade da mucosa do seio paranasal acometido. Um efeito de válvula permite que o ar entre, mas não saia da órbita. Se o septo orbitário estiver íntegro, a pressão intraorbitária pode ficar alta e uma síndrome compartimental pode se desenvolver ${ }^{(2-3)}$.

O diagnóstico é feito na maioria das vezes somente pela história do paciente e confirmado pelo exame externo e tomografia orbitária ${ }^{(4)}$.

Já foi sugerido como estadiar e um protocolo de manejo para o enfisema orbitário ${ }^{(5)}$. Porém, ainda não há consenso sobre o melhor tratamento para o enfisema orbitário, que depende da extensão do acometimento e do desenvolvimento de complicações ${ }^{(6)}$. Na maioria das vezes, por ser um quadro benigno, optase pela observação, já que a resolução espontânea e reabsorção do ar podem ocorrer em duas a três semanas ${ }^{(1)}$. 


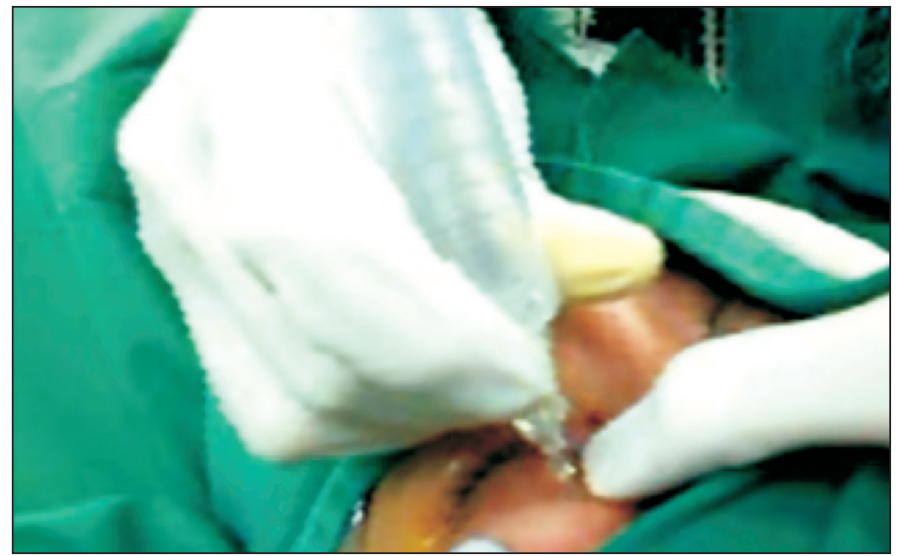

Figura 2 - Demonstração da punção com agulha fina na região súperomedial orbitária

As complicações, causadas pela síndrome compartimental orbitária, incluem aumento da pressão intraocular, proptose com alongamento do nervo óptico, neuropatia óptica compressiva/isquêmica e oclusão de artéria central da retina ${ }^{(1,7)}$. Outras complicações, associadas à fratura, incluem celulite orbitária e diplopia/restrição da motilidade ocular por encarceramento muscular ${ }^{(6)}$. No caso descrito, o tratamento de urgência foi realizado devido à redução de acuidade visual e ao aumento da PIO, além do aumento da dor referida pela paciente e a restrição de motilidade ocular. O tratamento deve ser imediato, e a demora em realizá-lo pode resultar em cegueira ${ }^{(8)}$.

A descompressão por agulha, procedimento descrito pela primeira vez em $1982^{(9)}$, é um procedimento simples, rápido e que pode evitar uma intervenção cirúrgica, como a cantotomia ou cantólise lateral ${ }^{(7)}$. Entretanto, não é isento de riscos, podendo ocorrer hemorragia retrobulbar, perfuração escleral e lesão do nervo óptico ${ }^{(2)}$.

No caso relatado existe história de trauma craniano leve, mas não foi evidenciada área de fratura no exame de tomografia computadorizada. Entretanto, áreas pequenas de defeito ósseo na lâmina papirácea do osso etmóide podem ser difíceis de serem visualizadas.

$\mathrm{O}$ antecedente de etilismo, que é fator de risco conhecido para aumento da incidência de injúrias relacionadas ao trau$\mathrm{ma}^{(10)}$, deve ser lembrado como causa de neuropatia óptica tóxica que também pode estar presente nesses pacientes.

Nesta paciente, a descompressão por agulha fina foi eficiente e nenhum outro procedimento foi necessário.

\section{CONCLUSÃO}

Os autores chamam a atenção para a punção com agulha para o tratamento do enfisema orbitário, procedimento bastante efetivo e que pode prevenir um possível comprometimento visual permanente.

\section{ABSTRACT}

Orbital emphysema is the abnormal presence of air in the orbit. Occurrence in the absence of orbital fracture is rare. We report a case of a 40-year-old female presenting unilateral orbital emphysema after vigorous nose blowing. She developed sudden visual loss as a result of elevated intraocular pressure and urgent treatment was required. She underwent an orbital decompression, performed using a 24-gauge needle puncture adjacent to the supraorbital notch. After treatment, she reported considerable decrease of symptoms.

Keywords: Emphysema/etiology; Orbital diseases; Pressure/ adverse effects, Visual acuity; Ocular hypertension; Case reports [Publication type]

\section{REFERÊNCIAS}

1. Shah N. Spontaneous subcutaneous orbital emphysema following forceful nose blowing: treatment options. Indian J Ophthalmol. 2007;55(5):395

2. Singh M, Phua VM, Sundar G. Sight-threatening orbital emphysema treated with needle decompression. Clin Experiment Ophthalmol. 2007;35(4):386-7.

3. Harmer SG, Ethunandan M, Zaki GA, Brennan PA. Sudden transient complete loss of vision caused by nose blowing after a fracture of the orbital floor. Br J Oral Maxillofac Surg. 2007;45(2):154-5.

4. Papadimitriou P, Ntomouchtsis A, Antoniades K. Delayed traumatic ocular emphysema: a case report. Oral Surg Oral Med Oral Pathol Oral Radiol Endod. 2006;102(6):e18-20

5. Hunts JH, Patrinely JR, Holds JB, Anderson RL. Orbital emphysema. Staging and acute management. Ophthalmology. 1994;101(5):960-6.

6. Bastion ML, Wong YC. A case of sneezing-related orbital emphysema treated by aspiration-decompression in the office. Ophthal Plast Reconstr Surg. 2006;22(6): $500-1$.

7. Lee SL, Mills DM, Meyer DR, Silver SM. Orbital emphysema. Ophthalmology. 2006;113(11):2113. e1-2.

8. Rubinstein A, Riddell CE, Akram I, Ahmado A, Benjamin L. Orbital emphysema leading to blindness following routine functional endoscopic sinus surgery. Arch Ophthalmol. 2005;123(10):1452. Comment in: Arch Ophthalmol. 2007; 125(3):433-4; author reply 434.

9. Linberg JV. Orbital emphysema complicated by acute central retinal artery occlusion: case report and treatment. Ann Ophthalmol. 1982;14(8):747-9.

10. Schermer CR, Omi EC, Ton-That H, Grimley K, Van Auken P, Santaniello J, Esposito TJ. A clustering of injury behaviors. J Trauma. 2008;65(5):1000-4. 